\title{
Receptors, Circuits, and Behaviors: New Directions in Chemical Senses
}

\author{
Donald B. Katz, ${ }^{1 \star}$ Hiroaki Matsunami, ${ }^{2 *}$ Dmitry Rinberg, ${ }^{3 *}$ Kristin Scott, ${ }^{4 *}$ Matt Wachowiak, ${ }^{5 *}$ and Rachel I. Wilson ${ }^{6}$ \\ ${ }^{1}$ Department of Psychology, Brandeis University, Waltham, Massachusetts 02454, ${ }^{2}$ Department of Molecular Genetics and Microbiology, Duke University \\ Medical Center, Durham, North Carolina 27710, ${ }^{3}$ Howard Hughes Medical Institute, Janelia Farm Research Campus, Ashburn, Virginia 20147, ${ }^{4}$ Department \\ of Molecular and Cell Biology, University of California, Berkeley, Berkeley, California 94720, ${ }^{5}$ Department of Biology, Boston University, Boston, \\ Massachusetts 02215, and ${ }^{6}$ Department of Neurobiology, Harvard Medical School, Boston, Massachusetts 02115
}

The chemical senses, smell and taste, are the most poorly understood sensory modalities. In recent years, however, the field of chemosensation has benefited from new methods and technical innovations that have accelerated the rate of scientific progress. For example, enormous advances have been made in identifying olfactory and gustatory receptor genes and mapping their expression patterns. Genetic tools now permit us to monitor and control neural activity in vivo with unprecedented precision. New imaging techniques allow us to watch neural activity patterns unfold in real time. Finally, improved hardware and software enable multineuron electrophysiological recordings on an expanded scale. These innovations have enabled some fresh approaches to classic problems in chemosensation.

Key words: chemosensation; taste; smell; receptor; circuit; behavior

The goal of this review is to highlight some recent advances in the study of taste and smell, particularly work published in the last 2 years. We will focus on four topics: (1) the selectivity of receptor cells, (2) the modulation of receptor input to the brain, (3) the role of active sampling, and (4) the importance of cognitive context. This review focuses on themes to be discussed in a Minisymposium at the Society for Neuroscience Annual Meeting on November 16, 2008, entitled "New Directions in Chemical Senses."

\section{Receptor cells: a new appreciation for specialization}

Chemosensory receptor cells are endowed with specialized receptor proteins that bind tastants and odorants. Each type of chemoreceptor cell expresses a different receptor gene (or combination of genes). These receptor genes specify its chemical selectivity. A general principle of chemosensory coding is that each type of receptor cell is typically activated by multiple different chemical ligands. The "accessory" olfactory system seems to be an exception to this rule, but in the "main" olfactory system and in the taste system, it has been traditionally thought that almost all individual receptor cells respond to more than one ligand (Scott, 2005; Dulac and Wagner, 2006; Zufall and Leinders-Zufall, 2007). Recently, however, it has become clear that certain receptors are very specific for particular chemical ligands, even in the

Received July 31, 2008; revised Sept. 8, 2008; accepted 0ct. 5, 2008.

This work was supported by grants from the National Institutes of Health (D.B.K., H.M., K.S., M.W., R.I.W.), the Howard Hughes Medical Institute (D.R.), the John Merck Scholars Program (K.S.), the Human Frontiers Science Program (H.M., R.I.W.), a Pew Scholar Award, a McKnight Scholar Award, a Sloan Foundation Research Fellowship, and Beckman Young Investigator Award (R.I.W.).

*D.B.K., H.M., D.R., K.S., and M.W. contributed equally to this work.

Correspondence should be addressed to Rachel I. Wilson, Department of Neurobiology, Harvard Medical School, 220 Longwood Avenue, Boston, MA 02115. E-mail: rachel_wilson@hms.harvard.edu.

DOI:10.1523/JNEUROSCI.3613-08.2008

Copyright $\odot 2008$ Society for Neuroscience ～0270-6474/08/2811802-04\$15.00/0 taste system and the main olfactory system. These specialized receptors might have evolved to ensure high detection sensitivity and discrimination acuity within a class of chemicals that has special behavioral relevance. Consistent with this idea, disrupting these specialized receptors can have a dramatic impact on behavioral responses to their cognate ligands.

An example of this is the human odorant receptor for androstenone and androstadienone. These odorants are derived from steroid hormones found in sweat and urine. Smelling one of these odorants can reportedly alter hormone levels in human subjects (Wyart et al., 2007). A new study reports the discovery of a specific human receptor for these odorants (Keller et al., 2007). In this study, hundreds of putative human odorant receptors were expressed in heterologous cells and screened for activation in response to various odorants. One receptor showed unusually strong responses to both androstenone and androstadienone, but not to any other odorants. Interestingly, some human subjects smell androstenone and androstadienone only weakly, or are unable to smell them altogether. Anosmia for androstenone was already known to have a genetic component, based on comparisons between identical and fraternal twins (Wysocki and Beauchamp, 1984). It turns out that these subjects tend to harbor a polymorphism in this particular receptor gene (Keller et al., 2007). The polymorphic variant odorant receptor did not respond to the steroidal odorants when expressed in heterologous cells. This study represents the first link between specific polymorphisms in a single odorant receptor gene and the altered perception of its cognate ligands.

Other discoveries of specialized odorant receptors come from the fruit fly Drosophila melanogaster. The fly olfactory and gustatory systems bear a strong resemblance to their vertebrate counterparts (Bargmann, 2006), although there are certainly also important differences. The powerful genetic tools available in the 
fly, and the relative simplicity of the fly brain, have made it a useful complement to vertebrate models in the field of chemosensation. A recent study showed that two types of Drosophila odorant receptor cells are highly sensitive to a male-specific fly pheromone (van der Goes van Naters and Carlson, 2007). Genetically silencing one of these cell types, or mutating the receptor gene it expresses, abolishes behavioral responses to this pheromone (Ejima et al., 2007; Kurtovic et al., 2007; Schlief and Wilson, 2007). Another type of Drosophila odorant receptor cell is highly specific for carbon dioxide, and the fly's innate behavioral response to this odorant is abolished by mutating one of the receptor genes expressed by this cell type (Jones et al., 2007). Carbon dioxide is released by both ripening fruit and by agitated flies and thus may carry important information in a variety of behavioral contexts (Suh et al., 2004; Faucher et al., 2006).

Specialized chemical receptors have also been recently revealed in the Drosophila taste system. This study reported a novel type of taste receptor cell in Drosophila that responds to carbonated water (Fischler et al., 2007). Calcium imaging revealed that these cells are very specific for this chemical substance. Genetically silencing these cells abolished the flies' innate attraction to carbonation, and genetically "triggering" these cells demonstrated that they are sufficient to produce this response. Although humans usually taste carbonation in the context of a sweet soda pop, the taste of carbonation means something different in the life of a fly. Because carbon dioxide and carbonic acid are byproducts of fermentation, carbonation may signal the presence of yeast, which is an excellent natural food source for Drosophila. Thus, these specialized receptor cells may have evolved to help the fly to locate a special source of food or to discriminate between foods of different nutritional quality.

\section{Early events in central processing: gating receptor input to the brain}

Sensation begins with receptor cells, but our sensory perceptions also depend on how the brain processes these inputs. The first opportunity for central sensory processing occurs at the presynaptic terminals of receptor cells. There, signal propagation onto postsynaptic neurons can be gated by presynaptic receptors that suppress neurotransmitter release. Several studies have recently demonstrated an important role for this type of early sensory processing in vivo in the mouse and fly olfactory system.

In the mouse, these studies exploited a new genetically encoded fluorescent indicator that reports changes in synaptic vesicle exocytosis. By expressing this reporter selectively in mouse olfactory receptor neurons (ORNs), Wachowiak and colleagues showed that in vivo neurotransmitter release from ORNs is powerfully suppressed by GABA release from local interneurons in the olfactory bulb (McGann et al., 2005). Moreover, much of this GABA is released tonically, in the absence of any odorant (Pírez and Wachowiak, 2008). Thus, if we imagine ORN axon terminals as a gateway for chemical information, it seems that these gates normally stand half-closed. These gates close down even more in the presence of a strong odorant, which recruits feedback inhibition that further inhibits ORN neurotransmitter release (Pírez and Wachowiak, 2008). This form of adaptive gain control may help keep olfactory bulb activity within useful dynamic range. In principle, these gates might be opened by descending input from higher brain centers (e.g., by cholinergic input from the basal forebrain or serotonergic input from the raphe), which is thought to suppress GABA release in the bulb (Gómez et al., 2005; Mandairon et al., 2006).

Similarly, new data from Drosophila show that ORN axon terminals represent an important regulatory checkpoint (Olsen and Wilson, 2008). Odorant-evoked activity in one type of ORN recruits GABA release from local interneurons, and this indirectly inhibits neurotransmitter release from other ORN types. The amount of lateral inhibition that is recruited by an odorant depends on the total ORN activity that this odorant elicits. Thus, the ORN input to each neuron seems to be normalized by input to the entire circuit.

Although all these studies highlight the important role for presynaptic inhibition at ORN axon terminals, there are also important differences between the mouse and fly olfactory circuits. Whereas presynaptic inhibition at fly ORN terminals reflects "lateral" cross talk between different ORN types, presynaptic inhibition at mouse ORN terminals occurs strictly between ORNs of the same type (McGann et al., 2005; Pírez and Wachowiak, 2008). In the mouse, lateral inhibition probably occurs at postsynaptic (not presynaptic) sites (Isaacson and Strowbridge, 1998; Schoppa et al., 1998; Margrie et al., 2001; Aungst et al., 2003; Arevian et al., 2008). Comparisons between these evolutionarily distant olfactory systems are helping us understand what aspects of olfactory coding represent deep common principles, and what aspects are specializations of a particular species.

Licks and sniffs: active sampling of the chemical environment Both taste and smell are active sensory modalities. Terrestrial vertebrates engage their chemical environment by licking, chewing, salivating, and sniffing. An insect actively spreads the tip of its proboscis onto a tastant before pumping it into its pharynx, and it can actively sample odorants by flicking its antenna and darting across plumes in the air. Several recent studies emphasize that chemosensory activity in the brain is shaped by the dynamics of these repetitive samples. Moreover, sensory perception modulates sampling behavior, and this in turn modulates neural activity and perception. Thus, chemosensation tends to evolve dynamically, at the level of both neurons and perception.

For example, during taste perception, licking draws tastant samples into the mouth repetitively. This produces repetitive activity patterns in gustatory cortex. Tastant-evoked spikes can be precisely timed to lick onset, and the relative timing of spikes in different neurons may carry information about the identity of the tastant (de Araujo et al., 2006; Stapleton et al., 2006).

Similarly, sniffs draw brief repetitive samples of air through the nose, creating repetitive patterns of ensemble activity in the olfactory bulb. Odorant-evoked spikes can be precisely timed to sniff onset, with different odorants evoking different temporal patterns in the same neuron (Bathellier et al., 2008). Although some olfactory perceptions can occur within a single sniff (Johnson et al., 2003; Uchida and Mainen, 2003), other tasks benefit from multiple sniffs (Abraham et al., 2004; Rinberg et al., 2006a). Multiunit recordings from the olfactory bulb in behaving rodents are helping to shed light on this process. Preliminary evidence shows that the neuronal activity in the bulb is modulated by the sniffing/breathing pattern, and suggests that the integration of information across sniffs happens in higher brain areas (Rinberg and Shusterman, 2007).

Sniffing is not static, however, and sniff rate can increase when a rodent detects or anticipates an odor (Kepecs et al., 2007; Verhagen et al., 2007). This increase in sampling rate had been thought to increase the amount of input to the olfactory bulb. However, a recent in vivo imaging study found that faster sniff rates actually suppress input to the bulb (Verhagen et al., 2007). This might help promote adaptation to a background odorant, 
thus promoting discrimination of new stimuli in the presence of the constant background.

\section{The role of task context: attention and hedonic valence}

Another topic of recent interest is the role of attention and other higher-order cognitive features in chemical perception. The study of these higher-order cognitive effects must obviously be performed in awake animals. Many older studies were performed in anesthetized animals (but see Chaput and Holley, 1980; Bhalla and Bower, 1997; Kay and Laurent, 1999). Now awake recordings are increasingly feasible, and previous studies should be critically reconsidered in the light of the recent discovery of important differences between awake and anesthetized states (Rinberg et al., 2006b).

Several studies have demonstrated that neural activity in the olfactory bulb is strongly modulated by task contingencies that are not explicitly olfactory (Kay and Laurent, 1999; Rinberg et al., 2006b; Fuentes et al., 2008). For example, changes in neural activity in the bulb can precede actual exposure to the odorant. These effects may be explained by descending inputs from higher brain areas to the bulb. Some of these effects may also reflect task-dependent modulation of sniffing, which could be regarded as another type of feedback. What is surprising about these results is how early in the olfactory system this modulation occurs.

There is some evidence suggesting that descending inputs to the bulb may modulate not only spike rate but also spike timing. A recent study reported that, during difficult odor discrimination tasks, strong synchronous oscillations appeared in the olfactory bulb field potential (Beshel et al., 2007). Strong oscillations were not present when the task was easy. Strong oscillations may increase synchrony in the timing of spike output from the bulb and could reflect increased attention. If so, then higher-order cognitive aspects of the task would be shaping neural activity at a remarkably early stage of processing, just one synapse downstream from receptor neurons.

Studies in the taste system also highlight the role of attention and hedonic valence. Attentional shifts can dramatically change behavioral responses to tastants and alter neural responses as early as primary gustatory cortex (Fontanini and Katz, 2006). In an attentive animal, cortical and behavioral responses to a tastant tend to reflect both the chemical identity of a tastant and its palatability. After attention lapses, both neural and behavioral responses become more tightly linked to palatability alone, and responses to chemically dissimilar substances with similar palatability become more similar to each other.

Altering the value of a taste stimulus also changes the way it is represented at an early processing stage. Pairing a sweet tastant with an aversive cue tends to suppress responses to this tastant in primary gustatory cortex (Grossman et al., 2008). This cannot be attributed to a decrease in lick rate, because it begins before any changes in sampling behavior. There is some evidence that this reflects increased input from the amygdala. Another study showed that allowing rats to eat until they are satiated also changes the way neurons in gustatory cortex respond to a tastant (de Araujo et al., 2006). Overall, tastant-evoked responses increase during hunger and decrease during satiety. Again, this can occur even when lick rate is unchanged. These results are additional evidence for the idea that primary gustatory cortex jointly encodes both the chemical identity of a tastant and its palatability.

\section{Conclusion}

These studies illustrate the diversity of current approaches to studying chemosensory processing. Amid this diversity, a few themes have emerged that unite many of these studies.

One theme is the remarkable role of receptor cells. Although some chemosensory receptor cells are rather broadly tuned, others are very specific. This may represent an early mechanism for extracting information about special chemical features of odorants and tastants. Moreover, receptor cells represent a major checkpoint for chemosensory signals: gating receptor input to the brain seems to be an important mechanism for shaping chemical perception. Thus, important aspects of chemical processing occur very early in nervous system. In the future, it will be interesting to see how manipulating these processing events affects chemosensory perception and behavior.

Another emerging theme is that higher cognitive features influence even the initial steps of central chemosensory processing. Neural correlates of alertness, attention, difficulty, expectation, and value are observed very early in these sensory systems. These features likely reflect descending modulatory input from higher brain centers. They also reflect the way perceptual judgments change active sampling behaviors and thereby modulate receptor input to the brain. These modulations contribute to the temporal complexity of chemosensory signals in the brain. A major challenge in the future will be to understand how neural activity on these different timescales contributes to an evolving percept of a smell or taste.

\section{References}

Abraham NM, Spors H, Carleton A, Margrie TW, Kuner T, Schaefer AT (2004) Maintaining accuracy at the expense of speed: stimulus similarity defines odor discrimination time in mice. Neuron 44:865-876.

Arevian AC, Kapoor V, Urban NN (2008) Activity-dependent gating of lateral inhibition in the mouse olfactory bulb. Nat Neurosci 11:80-87.

Aungst JL, Heyward PM, Puche AC, Karnup SV, Hayar A, Szabo G, Shipley MT (2003) Centre-surround inhibition among olfactory bulb glomeruli. Nature 426:623-629.

Bargmann CI (2006) Comparative chemosensation from receptors to ecology. Nature 444:295-301.

Bathellier B, Buhl DL, Accolla R, Carleton A (2008) Dynamic ensemble odor coding in the mammalian olfactory bulb: sensory information at different timescales. Neuron 57:586-598.

Beshel J, Kopell N, Kay LM (2007) Olfactory bulb gamma oscillations are enhanced with task demands. J Neurosci 27:8358-8365.

Bhalla US, Bower JM (1997) Multiday recordings from olfactory bulb neurons in awake freely moving rats: spatially and temporally organized variability in odorant response properties. J Comput Neurosci 4:221-256.

Chaput M, Holley A (1980) Single unit responses of olfactory bulb neurones to odour presentation in awake rabbits. J Physiol Paris 76:551-558.

de Araujo IE, Gutierrez R, Oliveira-Maia AJ, Pereira A Jr, Nicolelis MA, Simon SA (2006) Neural ensemble coding of satiety states. Neuron 51:483-494.

Dulac C, Wagner S (2006) Genetic analysis of brain circuits underlying pheromone signaling. Annu Rev Genet 40:449-467.

Ejima A, Smith BP, Lucas C, van der Goes van Naters W, Miller CJ, Carlson JR, Levine JD, Griffith LC (2007) Generalization of courtship learning in Drosophila is mediated by cis-vaccenyl acetate. Curr Biol 17:599-605.

Faucher C, Forstreuter M, Hilker M, de Bruyne M (2006) Behavioral responses of Drosophila to biogenic levels of carbon dioxide depend on life-stage, sex and olfactory context. J Exp Biol 209:2739-2748.

Fischler W, Kong P, Marella S, Scott K (2007) The detection of carbonation by the Drosophila gustatory system. Nature 448:1054-1057.

Fontanini A, Katz DB (2006) State-dependent modulation of time-varying gustatory responses. J Neurophysiol 96:3183-3193.

Fuentes RA, Aguilar MI, Aylwin ML, Maldonado PE (2008) Neuronal activity of mitral-tufted cells in awake rats during passive and active odorant stimulation. J Neurophysiol 100:422-430.

Gómez C, Briñón JG, Barbado MV, Weruaga E, Valero J, Alonso JR (2005) 
Heterogeneous targeting of centrifugal inputs to the glomerular layer of the main olfactory bulb. J Chem Neuroanat 29:238-254.

Grossman SE, Fontanini A, Wieskopf JS, Katz DB (2008) Learning-related plasticity of temporal coding in simultaneously recorded amygdalacortical ensembles. J Neurosci 28:2864-2873.

Isaacson JS, Strowbridge BW (1998) Olfactory reciprocal synapses: dendritic signaling in the CNS. Neuron 20:749-761.

Johnson BN, Mainland JD, Sobel N (2003) Rapid olfactory processing implicates subcortical control of an olfactomotor system. J Neurophysiol 90:1084-1094.

Jones WD, Cayirlioglu P, Kadow IG, Vosshall LB (2007) Two chemosensory receptors together mediate carbon dioxide detection in Drosophila. Nature 445:86-90.

Kay LM, Laurent G (1999) Odor- and context-dependent modulation of mitral cell activity in behaving rats. Nat Neurosci 2:1003-1009.

Keller A, Zhuang H, Chi Q, Vosshall LB, Matsunami H (2007) Genetic variation in a human odorant receptor alters odour perception. Nature 449:468-472.

Kepecs A, Uchida N, Mainen ZF (2007) Rapid and precise control of sniffing during olfactory discrimination in rats. J Neurophysiol 98:205-213.

Kurtovic A, Widmer A, Dickson BJ (2007) A single class of olfactory neurons mediates behavioural responses to a Drosophila sex pheromone. Nature 446:542-546.

Mandairon N, Ferretti CJ, Stack CM, Rubin DB, Cleland TA, Linster C (2006) Cholinergic modulation in the olfactory bulb influences spontaneous olfactory discrimination in adult rats. Eur $J$ Neurosci 24:3234-3244.

Margrie TW, Sakmann B, Urban NN (2001) Action potential propagation in mitral cell lateral dendrites is decremental and controls recurrent and lateral inhibition in the mammalian olfactory bulb. Proc Natl Acad Sci U S A 98:319-324.

McGann JP, Pírez N, Gainey MA, Muratore C, Elias AS, Wachowiak M (2005) Odorant representations are modulated by intra- but not interglomerular presynaptic inhibition of olfactory sensory neurons. Neuron 48:1039-1053.

Olsen SR, Wilson RI (2008) Lateral presynaptic inhibition mediates gain control in an olfactory circuit. Nature 452:956-960.
Pírez N, Wachowiak M (2008) In vivo modulation of sensory input to the olfactory bulb by tonic and activity-dependent presynaptic inhibition of receptor neurons. J Neurosci 28:6360-6371.

Rinberg D, Shusterman R (2007) Olfactory information processing in behaving mice. Cosyne Abstr, pp II-37.

Rinberg D, Koulakov A, Gelperin A (2006a) Speed-accuracy tradeoff in olfaction. Neuron 51:351-358.

Rinberg D, Koulakov A, Gelperin A (2006b) Sparse odor coding in awake behaving mice. J Neurosci 26:8857-8865.

Schlief ML, Wilson RI (2007) Olfactory processing and behavior downstream from highly selective receptor neurons. Nat Neurosci 10:623-630.

Schoppa NE, Kinzie JM, Sahara Y, Segerson TP, Westbrook GL (1998) Dendrodendritic inhibition in the olfactory bulb is driven by NMDA receptors. J Neurosci 18:6790-6802.

Scott K (2005) Taste recognition: food for thought. Neuron 48:455-464.

Stapleton JR, Lavine ML, Wolpert RL, Nicolelis MA, Simon SA (2006) Rapid taste responses in the gustatory cortex during licking. J Neurosci 26:4126-4138.

Suh GS, Wong AM, Hergarden AC, Wang JW, Simon AF, Benzer S, Axel R, Anderson DJ (2004) A single population of olfactory sensory neurons mediates an innate avoidance behaviour in Drosophila. Nature 431:854-859.

Uchida N, Mainen ZF (2003) Speed and accuracy of olfactory discrimination in the rat. Nat Neurosci 6:1224-1229.

van der Goes van Naters W, Carlson JR (2007) Receptors and neurons for fly odors in Drosophila. Curr Biol 17:606-612.

Verhagen JV, Wesson DW, Netoff TI, White JA, Wachowiak M (2007) Sniffing controls an adaptive filter of sensory input to the olfactory bulb. Nat Neurosci 10:631-639.

Wyart C, Webster WW, Chen JH, Wilson SR, McClary A, Khan RM, Sobel N (2007) Smelling a single component of male sweat alters levels of cortisol in women. J Neurosci 27:1261-1265.

Wysocki CJ, Beauchamp GK (1984) Ability to smell androstenone is genetically determined. Proc Natl Acad Sci U S A 81:4899-4902.

Zufall F, Leinders-Zufall T (2007) Mammalian pheromone sensing. Curr Opin Neurobiol 17:483-489. 